\title{
Prevalence of postoperative nausea and vomiting: the reality of our Ambulatory Unit - retrospective analysis
}

Galacho J., Pacheco J., Monteiro T.

Department of Anaesthesiology

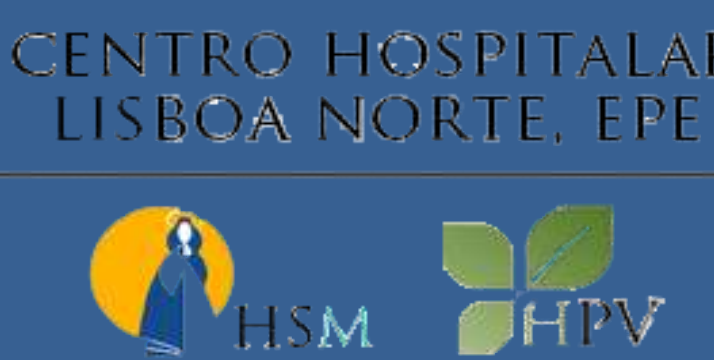

\section{BACKGROUND}

Postoperative nausea and vomiting (PONV) are the commonest complications after ambulatory surgery. PONV highly affects quality of life, causing great discomfort and dissatisfaction among patients, prolonged post-anesthesia care unit (PACU) stay, anticipated hospital readmission and increased overall health care costs. The goal of PONV prophylaxis is to decrease the incidence of PONV, and thus, patient distress and health care costs. Our goal was to measure the prevalence of PONV in our Ambulatory Surgery Unit, as well as to recognize whether PONV prophylaxis, according to PONV risk factors, and PONV treatment were adequate.

\section{MATERIALS AND METHODS}

A brief questionnaire, filled by the nursing staff, was applied to all patients submitted to surgery in our unit between October 16th and November 16th, 2017, in a total of 202 patients. 49 questionnaires lacking data were rejected. A total of 153 questionnaires were used. The data collected included type of procedure, presence of risk factors for the development of PONV according to Apfel's simplified risk score, antiemetics used in prophylaxis and treatment of PONV, and any episode of PONV.

\section{RESULTS AND DISCUSSION}

According to Apfel's simplified risk score for PONV in adults, only in $53.59 \%$ of patients the PONV was adequately administered, however, the great majority of patients had no episodes of PONV, those occurring in only $7.8 \%$ of patients.
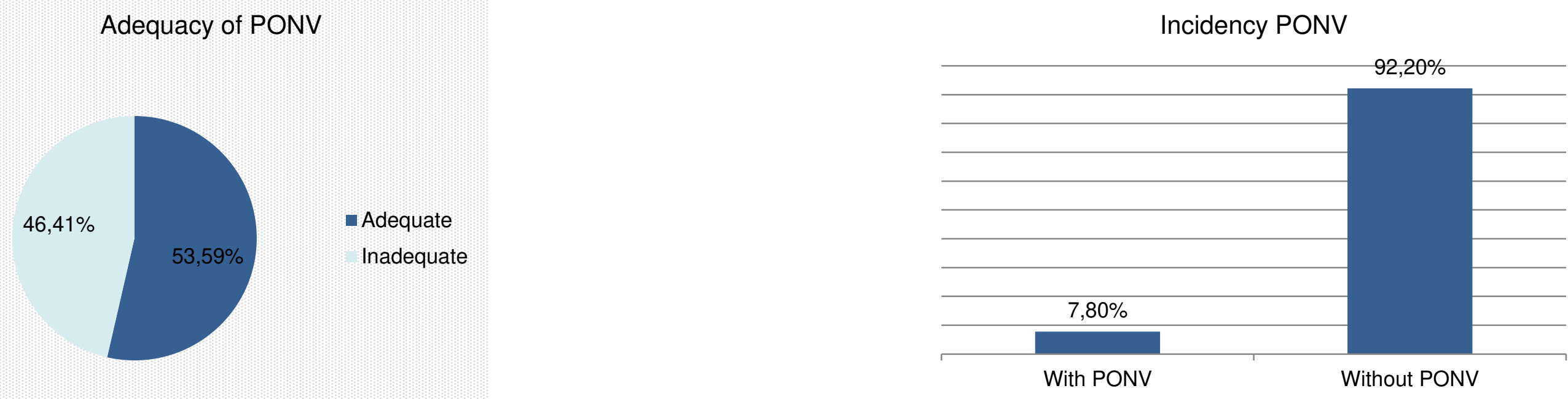

Among patients who had at least an episode of PONV, only $16.6 \%$ had inadequate PONV prophylaxis.

The most commonly used drug was dexamethasone (4mg IV), followed by ondansetron (4mg IV) and droperidol (0.625-1.25mg IV). Among the patients who presented with PONV in the PACU, only $25 \%$ received adequate treatment, as the majority of patients were medicated with metoclopramide IV, leading to subsequent PONV episodes in $41.6 \%$ of these patients.

Adequacy of Prophylaxis of PONV in Patients who had PONV

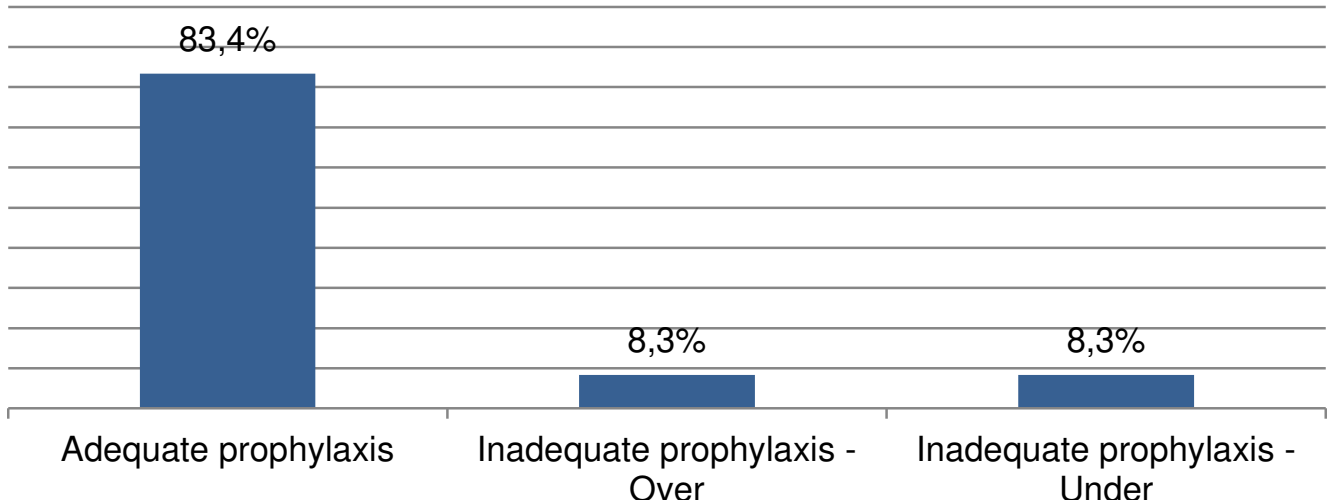

Relation between PONV recurrence and PONV treatment adequacy

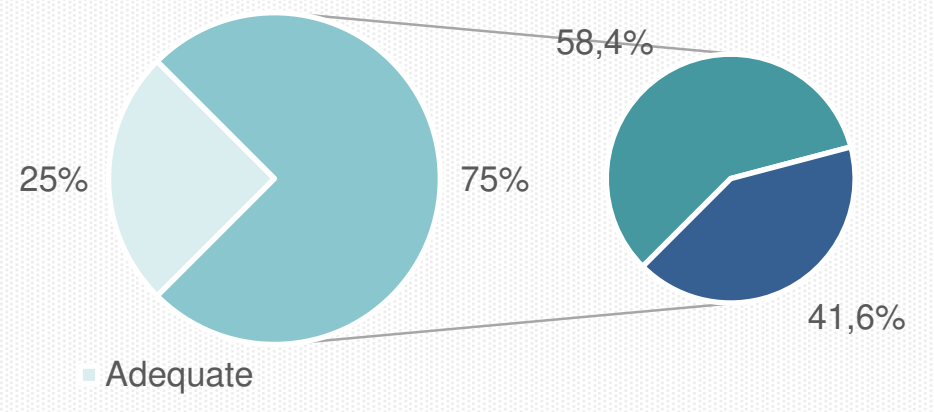

- Innadequate treatment without recurrence of PONV - Innadequate treatment with recurrence of PONV

\section{CONCLUSION}

The overall prevalence of PONV in our Ambulatory Surgery Unit is low, although adequate PONV prophylaxis is lower than expected. Interestingly, the great majority of patients who suffered PONV had previous adequate PONV prophylaxis. The treatment of PONV in the PACU was improper in the vast majority of cases, leading to subsequent episodes of PONV, prolonged PACU stay and health care costs.

\section{REFERENCES}

1. Vieira V. et al. Recomendações portuguesas para a profilaxia e tratamento das náuseas e vómitos no pós-operatório em cirurgia de ambulatório. Revista Sociedade Portuguesa de Anestesiologia. 2011; 20(2):10-21 